\title{
Astragaloside IV sensitizes non-small cell lung cancer cells to cisplatin by suppressing endoplasmic reticulum stress and autophagy
}

\author{
Song-Tao Lai ${ }^{1,2}$, Yan Wang ${ }^{3}$, Fei Peng ${ }^{4}$ \\ ${ }^{1}$ Department of Radiation Oncology, Fudan University Shanghai Cancer Center, Shanghai, China; ${ }^{2}$ Department of Oncology, Shanghai Medical \\ College, Fudan University, Shanghai, China; ${ }^{3}$ Department of Medical Oncology, Changzheng Hospital, Second Military Medical University, \\ Shanghai, China; ${ }^{4}$ Department of Nursing, Changzheng Hospital, Second Military Medical University, Shanghai, China \\ Contributions: (I) Conception and design: F Peng, ST Lai; (II) Administrative support: F Peng, Y Wang; (III) Provision of study materials or patients: \\ F Peng, S Lai; (IV) Collection and assembly of data: S Lai, Y Wang; (V) Data analysis and interpretation: S Lai, Y Wang; (VI) Manuscript writing: \\ All authors; (VII) Final approval of manuscript: All authors. \\ Correspondence to: Fei Peng. Department of Nursing, Changzheng Hospital, No. 415 Fengyang Road, Shanghai 200003, China. \\ Email: wyp8037@163.com.
}

Background: Cisplatin is an effective chemotherapeutic drug for treating various cancers including nonsmall cell lung cancer (NSCLC), but resistance to cisplatin remains the main limitation to its use in clinic. Astragaloside IV (AS-IV), which is derived from Astragalus membranaceus, has been proven to participate in various anti-cancer activities including anti-cancer, anti-oxidative, and anti-inflammatory functions.

Method: In this study, we explored the role of AS-IV in cisplatin chemoresistance to NSCLC cells by establishing cisplatin-resistant the NSCLC cell lines, A549 ${ }^{\mathrm{Cis}}$ and $\mathrm{H} 1299^{\mathrm{Cis}}$.

Results: Cisplatin inhibited viability and promoted apoptosis of A549 $9^{\mathrm{Cis}}$ and $\mathrm{H} 1299^{\mathrm{Cis}}$ cells in a dosedependent manner. In addition, cisplatin upregulated the levels of autophagy-related proteins (Beclin1, LC3 II/I) and endoplasmic reticulum (ER) stress-related proteins (glucose regulated protein 78: GRP78, protein kinase $\mathrm{R}$ (PKR)-like endoplasmic reticulum kinase: PERK), indicating that cisplatin caused autophagy and ER stress in NSCLC cells. However, treatment combined with AS-IV dose-dependently suppressed cell viability and increased the cell apoptosis rate in $\mathrm{A} 549^{\mathrm{Cis}}$ and $\mathrm{H} 1299^{\mathrm{Cis}}$ cells, suggesting that AS-IV elevated the anti-tumor role of cisplatin in NSCLC cells. AS-IV treatment suppressed the expression of GRP78 and Beclin1. Inhibition of ER stress or autophagy both counteracted the inhibitory effect of AS-IV on chemoresistance to cisplatin in NSCLC cells.

Conclusions: AS-IV sensitized NSCLC cells to cisplatin through suppressing ER stress and autophagy. This study provides a novel strategy of cisplatin combined with AS-IV for the treatment of cisplatin-resistant NSCLC patients.

Keywords: Astragaloside IV (AS-IV); non-small cell lung cancer (NSCLC); cisplatin; endoplasmic reticulum stress (ER stress); autophagy

Submitted May 09, 2020. Accepted for publication Jul 09, 2020.

doi: 10.21037/jtd-20-2098

View this article at: http://dx.doi.org/10.21037/jtd-20-2098 


\section{Introduction}

Non-small cell lung cancer (NSCLC) is one of the most common cancers and the primary cause of cancer-related death around the world (1). At present, supplementary therapy used to treat NSCLC patients following surgical operation, and cisplatin is widely considered as a first-line chemotherapeutic agent for NSCLC patients (2). However, cisplatin resistance remains a main obstacle to achieving successful chemotherapy (3). The cytotoxic mechanism of cisplatin includes DNA damage and the suppression of DNA synthesis in cancer cells, which prevent or increase cancer cell death by regulating a range of signaling pathways including autophagy and endoplasmic reticulum (ER) stress $(4,5)$.

The ER is an important organelle for protein folding and maturation in eukaryotic cells. ER stress can be triggered by exposure to chemotherapeutic agents and the accumulation of misfolded proteins $(6,7)$. The accumulation of misfolded proteins in the ER cavity contributes to ER stress and the activation of subsequent unfolded protein response (UPR), thereby initiating the expression of chaperone proteins (8). Moderate ER stress promotes survival of cancer cells and enhances resistance to chemotherapy $(9,10)$.

Autophagy is a common cellular process that degrades aggregated or misfolded proteins in cells and damaged organelles to maintain cell homeostasis (11). It is also a form of programmed cell death, which is closely related to apoptosis (12). Previous studies have reported that autophagy plays a vital role in the drug resistance of cancer cells. Bao et al. reported that induction of autophagy contributes to cisplatin resistance in human ovarian cancer cells (13), while Su et al. demonstrated that autophagy inhibition enhances cisplatin sensitivity in nasopharyngeal carcinoma cells (14). However, knowledge concerning the precise mechanism of autophagy resistance to cisplatin in NSCLC treatment remains extremely limited.

Astragaloside IV (AS-IV), a major active component of Astragalus membranaceus, has anti-cancer, anti-oxidative, and anti-inflammatory functions (15-17). Although ASIV is a potential treatment drug for NSCLC (17), the relevant mechanism has not been elucidated. Thence, this study aimed to investigate the effect of AS-IV on cisplatin chemosensitivity in NSCLC cells, and the relationship with endoplasmic reticulum stress and autophagy. In the current study, the results of western blot suggested that cisplatin seriously induced increasing of ER stress-related proteins glucose regulated protein 78 (GRP78) and protein kinase
$\mathrm{R}$ (PKR)-like endoplasmic reticulum kinase (PERK), also enhanced expression levels of autophagy-related proteins Beclin1 and LC3 II/I. Fortunately, treatment combined with AS-IV partly reversed these effects. Thus, we inferred that AS-IV increased the chemosensitivity of NSCLC cells to cisplatin through suppressing ER stress and autophagy.

\section{Methods}

\section{Reagents and cell culture}

NSCLC cell lines (A549, H1299) were purchased from the American Type Culture Collection (ATCC). Cisplatinresistant A549 and H1299 cell lines, A549Cis and H1299Cis, were established by constant exposure to cisplatin through a process described previously (18). A549Cis and H1299Cis cells were cultured in RPMI-1640 medium (Gibco, Rockville, MD, USA) supplemented with $2 \mu \mathrm{M}$ cisplatin and $10 \%$ fetal bovine serum (FBS) at $37^{\circ} \mathrm{C}$ with $5 \% \mathrm{CO}_{2}$. A549Cis and H1299Cis cells were moved to the cisplatinfree medium for 2 weeks before subsequent experiments were performed in order to eliminate the interference of residual cisplatin. AS-IV, cisplatin, and rapamycin were obtained from Sigma (St. Louis, MO, USA).

\section{Cell viability assay}

Cell Counting Kit-8 (CCK-8) assay was carried out to detect cell viability. Different groups of cells were seeded into 96 -well plates at a density of $2 \times 10^{3}$ cells per well, in triplicate. After cells were treated with each concentration of cisplatin for $24 \mathrm{~h}, 10 \mu \mathrm{L} /$ well of CCK-8 solution (Dojindo, Tokyo, Japan) was added, and the cells were incubated in the dark at $37^{\circ} \mathrm{C}$ for another $2 \mathrm{~h}$. The optical density (OD) was determined under $490 \mathrm{~nm}$.

\section{Cell apoptosis assay}

Cell apoptosis was detected by Hoechst 33258 stain analysis. In brief, $2 \times 10^{5}$ cells per well were washed with phosphatebuffered saline (PBS) twice. Then, $1 \mathrm{~mL}$ of Hoechst 33258 reagent (Beyotime, Nantong, China) was added to each well, and the cells were incubated at $37{ }^{\circ} \mathrm{C}$ for $30 \mathrm{~min}$ in the dark. Next, the Hoechst 33258 reagent was removed, and cells were washed with PBS 3 times ( $5 \mathrm{~min} \times 3$ times). Morphological changes of apoptotic cells were observed under an inverted fluorescence microscope, and images were captured. 


\section{Flow cytometry}

Cells were harvested to detecte cell apoptosis after $48 \mathrm{~h}$ transfection. Cells were washed with pre-cooled PBS three times, followed by being re-suspended using binding buffer to a concentration of $1 \times 10^{6} / \mathrm{mL}$ to $5 \times 10^{6} / \mathrm{mL}$. Then, $100 \mu \mathrm{L}$ cell suspension was moved into a $5-\mathrm{mL}$ tube, to which $5 \mu \mathrm{L}$ of Annexin V/fluorescein isothiocyanate (FITC) and $5 \mu \mathrm{L}$ of propidium iodide (PI) were added, followed by incubating the tube under the dark for $15 \mathrm{~min}$. Then, $400 \mu \mathrm{L}$ of $1 \times$ Annexin $\mathrm{V}$ binding buffer was added into the tube. Cell apoptosis was analyzed using a FACScan flow cytometer (BD Biosciences, USA).

\section{Western blot analysis}

The extraction of total protein from the treated cells was carried out using radioimmunoprecipitation assay (RIPA) lysis buffer (Beyotime, Nantong, China). The concentration of protein was quantified with bicinchoninic acid (BCA) protein measurement kit (Thermo Fisher Scientific, USA). Proteins were separated by $10 \%$ sodium dodecyl sulfate-polyacrylamide gel electrophoresis (SDSPAGE) gel and then transferred onto polyvinylidene fluoride (PVDF) membranes (Millipore, Boston, MA, USA). The membrane was blocked with $5 \%$ skim milk at room temperature for $2 \mathrm{~h}$, and then incubated with anti-GRP78 antibody, anti-PERK antibody, anti-Beclin1 antibody, anti-LC3 I/II antibody, and anti-GAPDH antibody (Cell Signaling Technology, USA) at $4{ }^{\circ} \mathrm{C}$ overnight. Next day, the relative secondary antibody was added, and the membrane was incubated at room temperature for $1 \mathrm{~h}$. Then, enhanced chemiluminescence (ECL) reagent was added, and the membranes were detected by chemiluminescence (GE Healthcare, Piscataway, NJ, USA).

\section{Statistical analysis}

All data are presented as the mean \pm standard deviation (SD) and were analyzed by SPSS19.0. The Student's $t$-test was used to compare means of two groups and one-way analysis of variance (ANOVA) was used for comparing means of multiple samples. Values of $\mathrm{P}<0.05$ were considered statistically significant.

\section{Results}

\section{Cisplatin inbibited cell viability and induced apoptosis in cisplatin-resistant NSCLC cells}

In order to estimate the cytotoxicity of cisplatin treatment on cisplatin-resistant NSCLC cells, A549Cis and H1299Cis cells were incubated with each dose of cisplatin for $24 \mathrm{~h}$. CCK-8 assay was used to detect the cell viability rate. The data showed that cisplatin application suppressed cell viability in both A549Cis and H1299Cis cells (Figure 1A). Meanwhile, results from Hoechst 33258 stain analysis revealed that cisplatin dose-dependently induced apoptosis in A549Cis and H1299Cis cells (Figure 1B). Hence, we can surmise that cisplatin inhibited cell viability and induced apoptosis in cisplatin-resistant NSCLC cells.

\section{Cisplatin induced ER stress and autophagy in cisplatin- resistant NSCLC cells}

To further investigate whether ER stress and autophagy are related to cisplatin-induced cell apoptosis in A549Cis and H1299Cis cells, we examined the expression of ER stressrelated and autophagy-related proteins following cisplatin treatment by Western blot. After A549Cis and H1299Cis cells were treated with each concentration of cisplatin $(0,20$, and $60 \mu \mathrm{M}$ ) for $24 \mathrm{~h}$ respectively, the expression of GRP78 and PERK (two kinds of ER stress-related proteins) and autophagy-related proteins (Beclin1, LC3 II/I) significantly increased in a dose-dependent manner (Figure $2 A, B, C, D$ ). These results indicate that cisplatin induced ER stress and autophagy in A549Cis and H1299Cis cells.

\section{AS-IV augmented the anti-tumor effect of cisplatin dose- dependently}

The effect of AS-IV on the chemoresistance of NSCLC cells to cisplatin was explored. The results suggested that the combination of AS-IV and cisplatin suppressed cell viability and increased the cell apoptosis rate in A549Cis and H1299Cis cells in a dose-dependent manner compared with the cisplatin $20 \mu \mathrm{M}$ treatment group (Figure $3 A, B, C, D$ ). These findings demonstrate that AS-IV enhanced the anti-tumor effect of cisplatin in NSCLC cells in a dosedependent manner. 


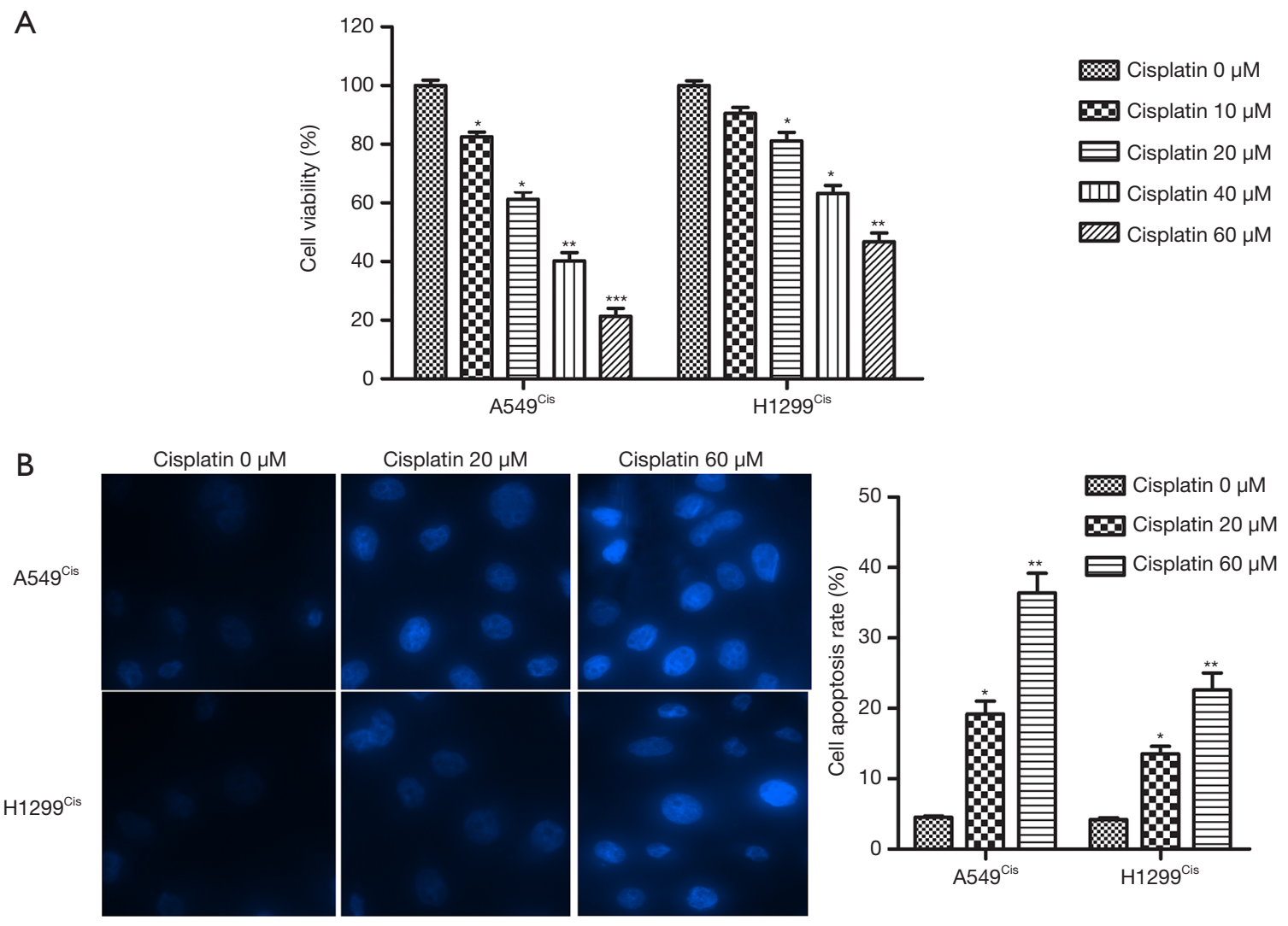

Figure 1 Cisplatin inhibited cell viability and induced apoptosis in cisplatin-resistant NSCLC cells. Cisplatin-resistant NSCLC cell lines, A549 ${ }^{\mathrm{Cis}}$ and $\mathrm{H} 1299^{\mathrm{Cis}}$, were established and treated with each concentration of cisplatin. (A) Cell viability was measured by CCK-8 assay. (B) Cell apoptosis was detected by Hoechst 33258 stain analysis ( $\times 400$ magnification). Data are expressed as mean \pm SD of three independent experiments. ${ }^{*} \mathrm{P}<0.05,{ }^{* *} \mathrm{P}<0.01$, and ${ }^{* *} \mathrm{P}<0.001$ compared with the cisplatin $0 \mu M$ group. NSCLC, non-small cell lung cancer.

\section{AS-IV sensitized NSCLC cells to cisplatin through suppressing ER stress and autophagy}

We further examined the molecular changes of NSCLC cells under AS-IV cotreatment to reveal the underlying mechanism of AS-IV sensitization in the chemosensitivity to cisplatin. Western blot results revealed that the expressions of GRP78 and Beclin1 were both markedly downregulated after co-administration with AS-IV (Figure 4A), indicating that AS-IV might augment the antitumor effect of cisplatin through inhibiting ER stress and autophagy. To verify our hypothesis, autophagy activator, rapamycin (100 nM), and ER stress inducer, tuniamycin $(5 \mu \mathrm{g} / \mathrm{mL})$, were used to treat the cells. Our data showed that both rapamycin and tuniamycin treatment increased cell viability and decreased cell apoptosis in A549Cis and H1299Cis cells, as compared with the AS-IV $16 \mathrm{ng} / \mathrm{mL}$ group. This suggests that induction of autophagy or ER stress counteracted the inhibitory effect of AS-IV on chemoresistance to cisplatin in NSCLC cells (Figure 4B,C,D,E). Our data demonstrate that AS-IV sensitized NSCLC cells to cisplatin through suppressing ER stress and autophagy.

\section{Discussion}

NSCLC is one of the most common malignant tumors, with cisplatin being the predominant first-line chemotherapy for NSCLC patients. However, acquired drug resistance limits the application of cisplatin (19). As a chemotherapeutic agent, cisplatin causes DNA lesioning and the suppression of DNA synthesis in cancer cells. Cisplatin-caused DNA damage can activate various signaling pathways which induce cell death, mainly through apoptosis-related pathways (20). Recent research indicates that cisplatin- 
A

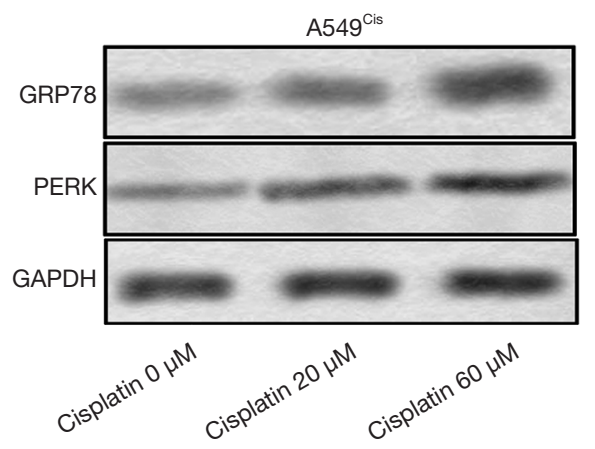

B

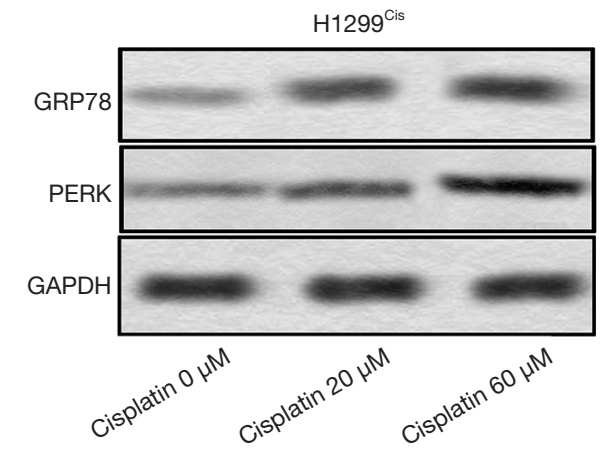

C

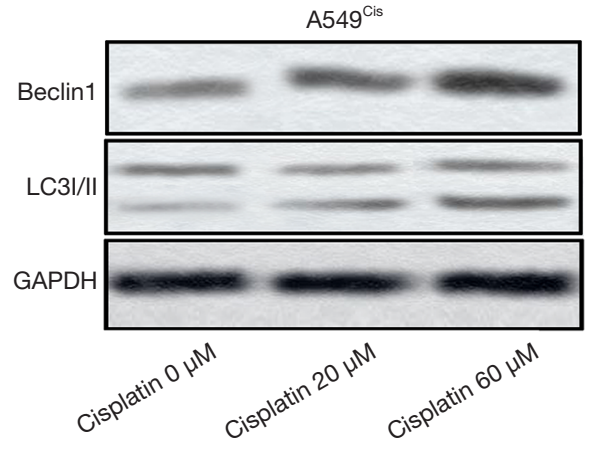

D

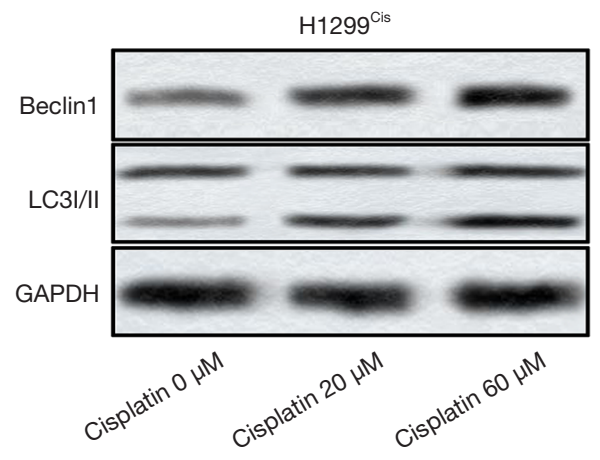

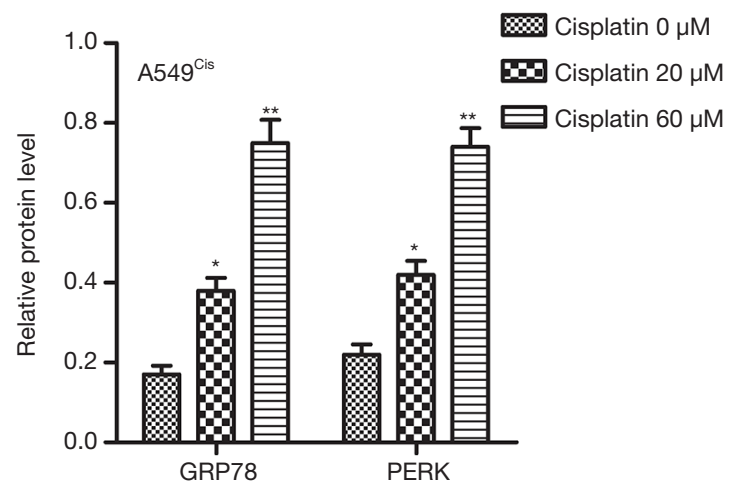
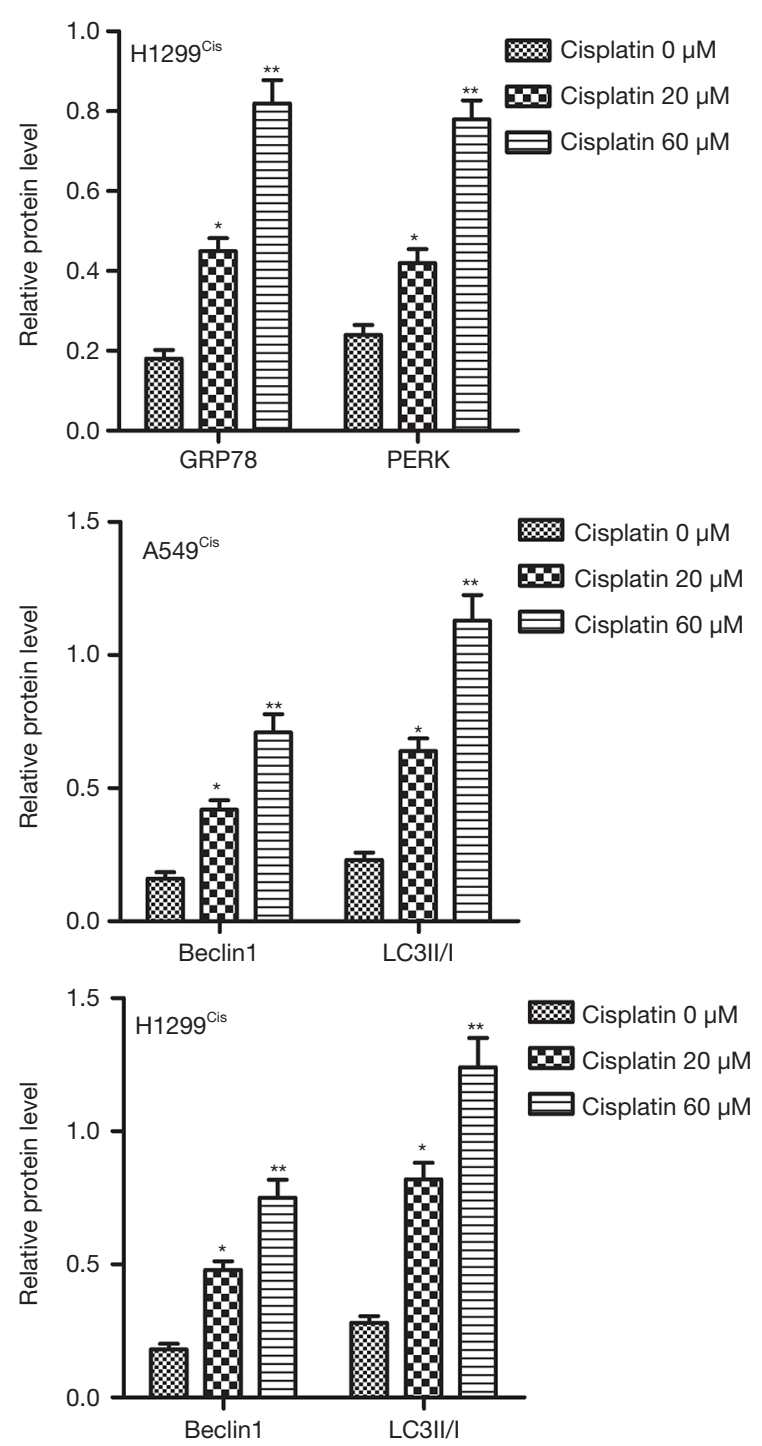

Figure 2 Cisplatin induced ER stress and autophagy in cisplatin-resistant NSCLC cells. A549 ${ }^{\mathrm{Cis}}$ and $\mathrm{H} 1299^{\mathrm{Cis}}$ cells were treated with each concentration of cisplatin. (A,B,C,D) Relative expression of GRP78, PERK, Beclin1, and LC3I/II in A549 ${ }^{\mathrm{Cis}}$ and H1299 $9^{\mathrm{Cis}}$ cells were determined by Western blot. Data are expressed as mean $\pm \mathrm{SD}$ of three independent experiments. ${ }^{*} \mathrm{P}<0.05$ and ${ }^{* *} \mathrm{P}<0.01$ compared with cisplatin $0 \mu \mathrm{M}$ group. ER, endoplasmic reticulum; NSCLC, non-small cell lung cancer. 


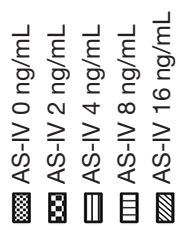

है $\vec{\xi} \overrightarrow{~ ह ै ~} \frac{\vec{\xi}}{\mathrm{g}}$

के के के ठ़ ट

$\geq \geq \geq \geq \geq$

它定它定它

圆目目 $\mathbb{B}$

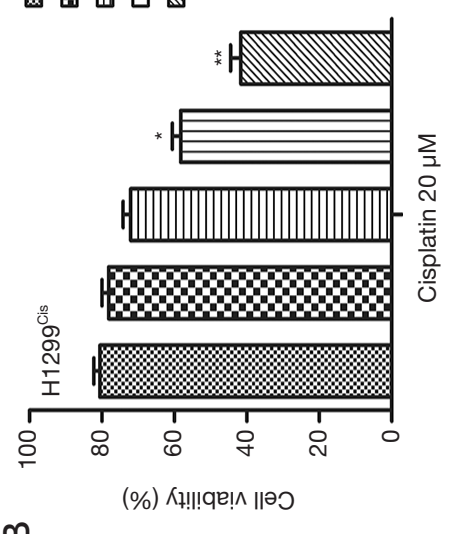

$\infty$

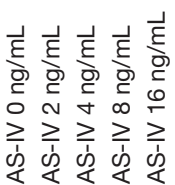

圆目目

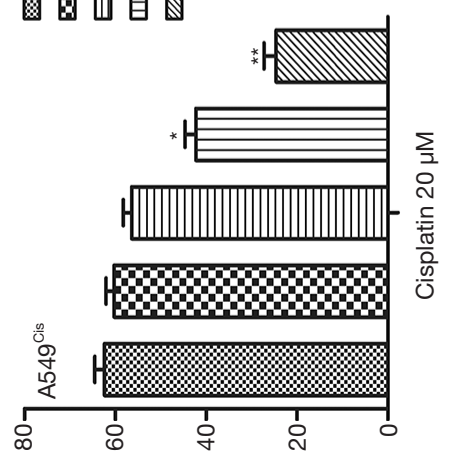

(\%) К‼!q!!^ ||əว

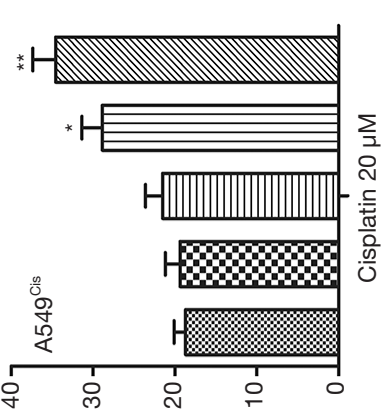

(\%) әəҐеג s!soldode $\| ә \supset$
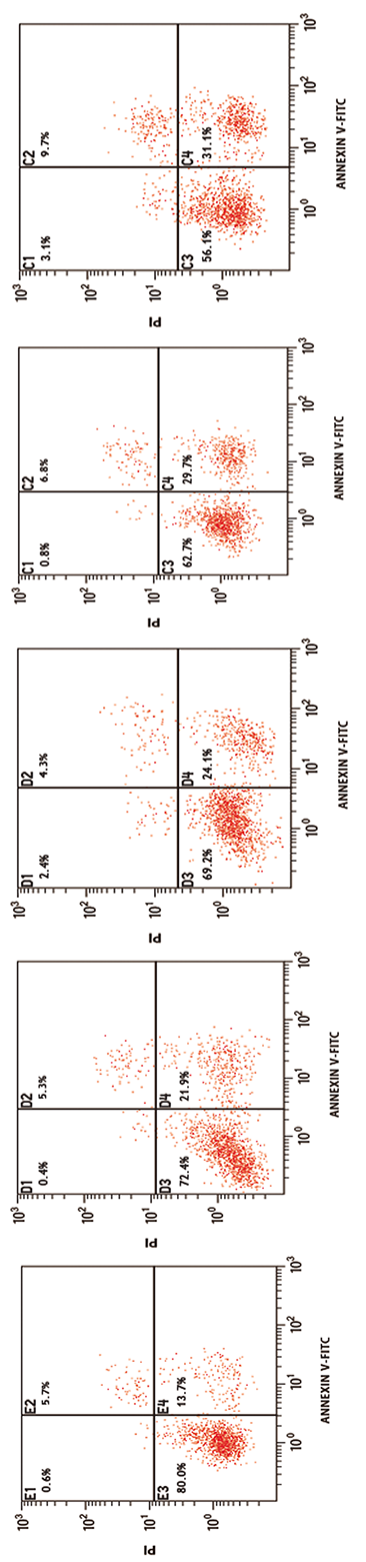

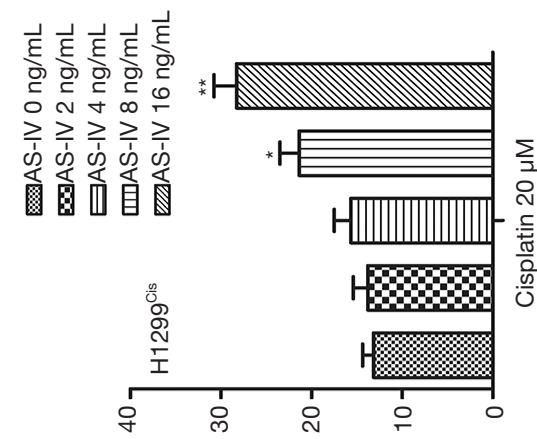

(\%) әəңеג s!soldode ॥ə弓
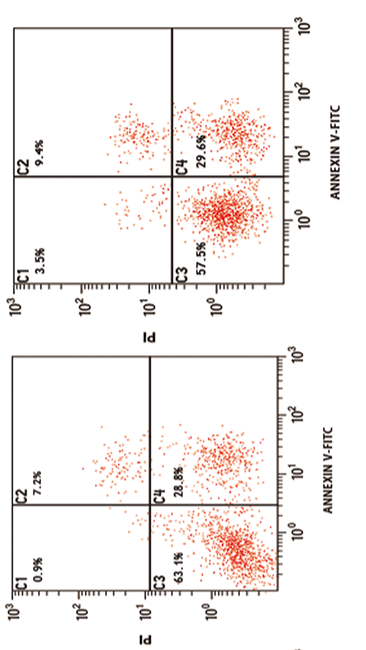

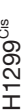

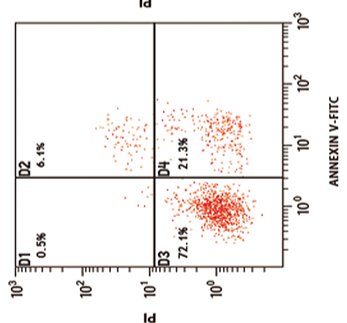

苛 会

$\stackrel{ \pm}{\Psi}$

寻

표

D

苛

Ð

营

$\sum$

$\stackrel{2}{\circ}$

도

索

Ð

Ð

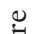

उ

क त क

\&

ลे $\frac{\pi}{2}$

공

궁

ฮ

㻤

号

$\therefore ن$ के

突

की

正 $\infty$

ग

8 -

节泀

离

4 过

艺

包

के

节章

击

$\mp 0$

용

$\stackrel{\Xi}{\square}$

过

क्षे

is

先

m

范 

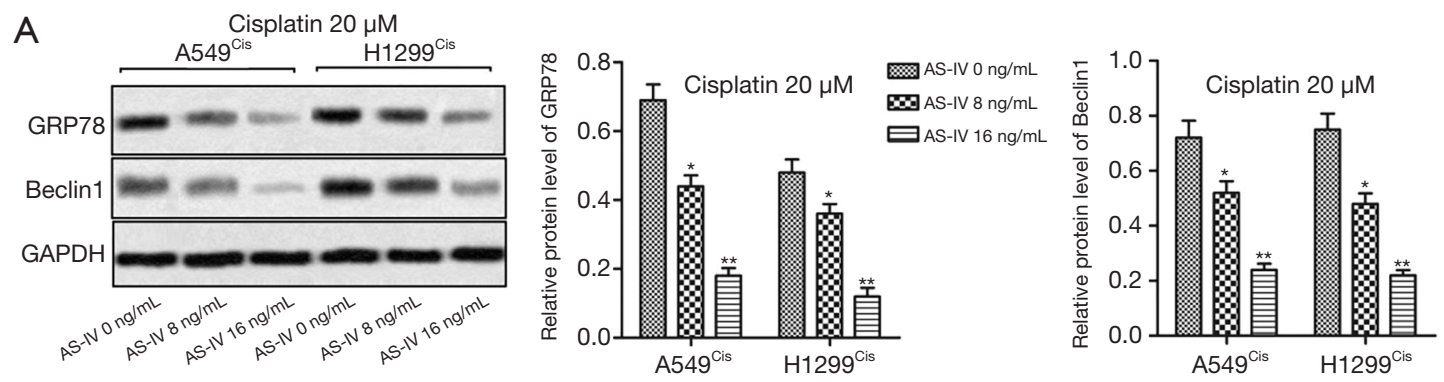

B

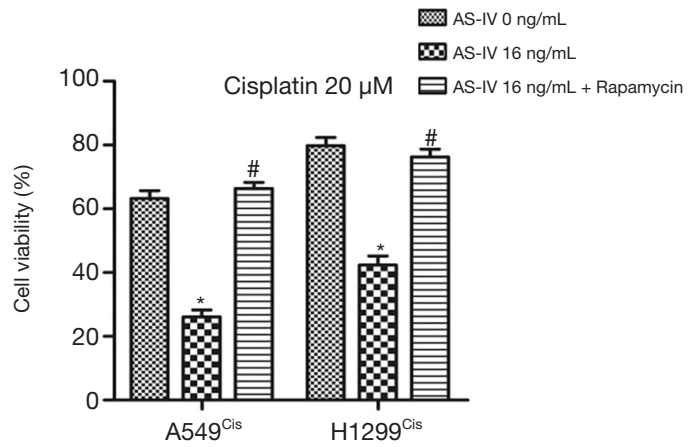

C

AS-IV $0 \mathrm{ng} / \mathrm{mL}$ EDAS-IV $16 \mathrm{ng} / \mathrm{mL}$

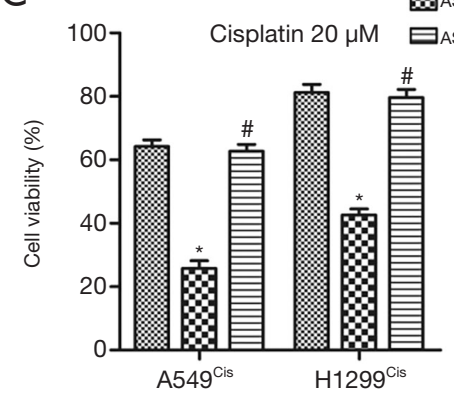

D

Cisplatin $20 \mu \mathrm{M}$
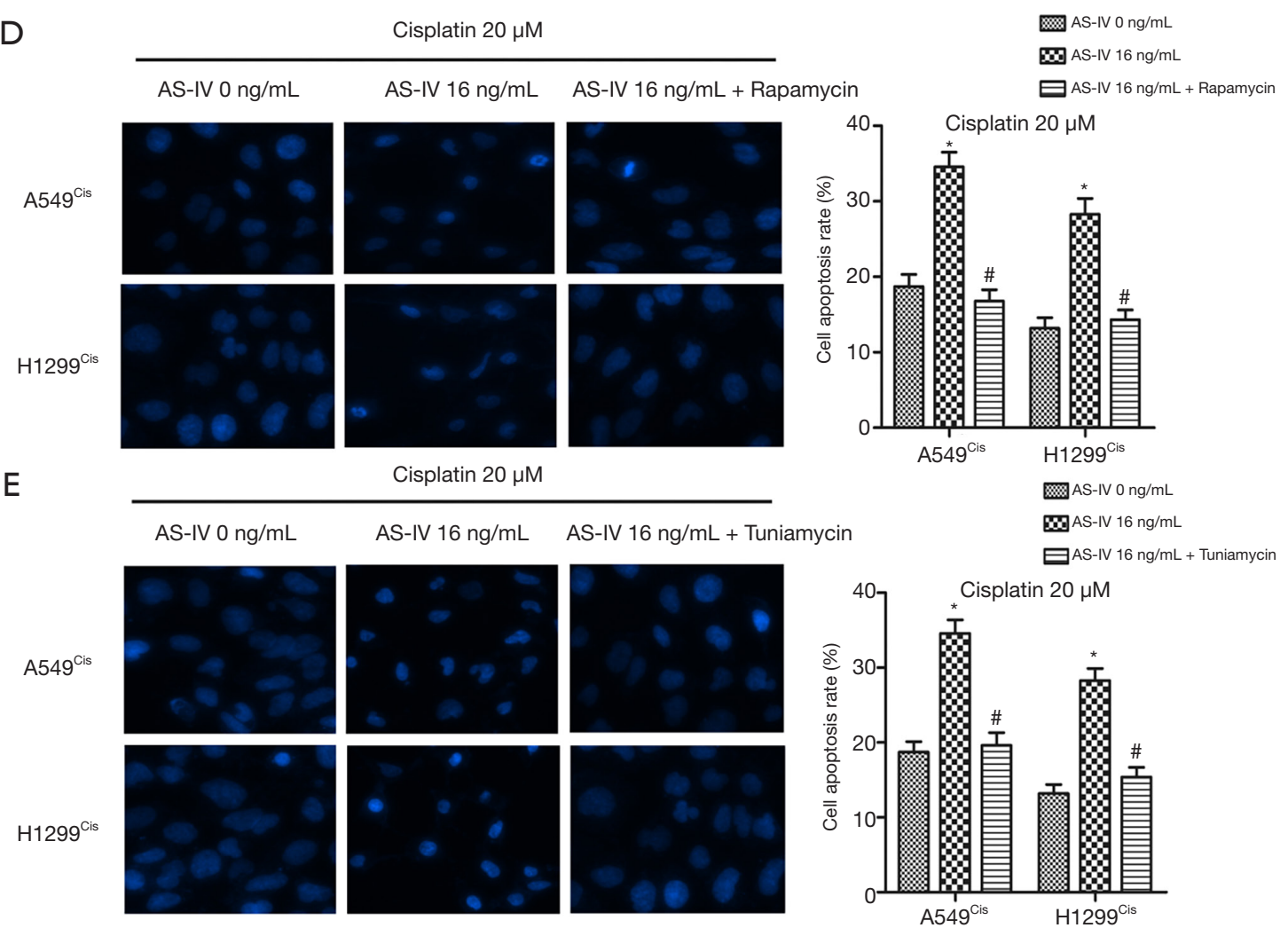

Figure 4 AS-IV sensitized NSCLC cells to cisplatin through suppressing ER stress and autophagy. A549 ${ }^{\mathrm{Cis}}$ and H1299 ${ }^{\mathrm{Cis}}$ cells were treated with $20 \mu \mathrm{M}$ cisplatin combined with AS-IV along with rapamycin or tuniamycin. (A) Relative expression of GRP78 and Beclin1 in A549 ${ }^{\text {Cis }}$ and $\mathrm{H} 1299^{\mathrm{Cis}}$ cells were assessed by Western blot. (B,C) Cell viability was measured through CCK-8 assay. (D,E) Cell apoptosis rate was assessed by Hoechst 33258 stain analysis ( $\times 400$ magnification). Data are expressed as mean \pm SD of three independent experiments. ${ }^{*} \mathrm{P}<0.05$ and ${ }^{* *} \mathrm{P}<0.01$ compared with the AS-IV $0 \mathrm{ng} / \mathrm{mL}$ group; $\# \mathrm{P}<0.05$ compared with the AS-IV $16 \mathrm{ng} / \mathrm{mL}$ group. AS-IV, astragaloside IV; NSCLC, non-small cell lung cancer. 
induced ER stress and autophagy can inhibit cisplatininduced apoptosis in cancer cells (5). Therefore, suppressing ER stress and autophagy induced by cisplatin might help to augment the anti-tumor effect of cisplatin. In our present study, we found that AS-IV, a major active component of Astragalus membranaceus, can sensitize NSCLC cells to cisplatin by suppressing ER stress and autophagy.

ER is an essential intracellular organelle in eukaryotic cells with multiple functions including protein synthesis, protein folding, stress reaction, and calcium ion level modulation (21). It was reported that changes in the tumor cell microenvironment or the effects of anti-tumor drugs can provoke ER stress, resulting in the accumulation of unfolded proteins in the ER lumen $(22,23)$. ER stress can trigger a UPR, which decreases the burden of protein processing in the ER and increases the level of ER molecular chaperones such as GRP78 and the ER stress sensor protein, PERK (4). It has been shown that mild ER stress promotes cell survival through UPR to mitigate ER stress (24). However, severe ER stress can cause cell apoptosis by activating the downstream apoptotic signaling pathway (25). Lin et al.'s study reported that human lung cancer cells acquired cisplatin-resistance through ER stress (26). Zhang et al. also indicated that cisplatin induced ER stress in U251 human glioma cells (4). Similarly, our present study suggests that cisplatin suppressed cell viability and triggered apoptosis in cisplatin-resistant NSCLC cells; the application of cisplatin upregulated the expression of GRP78 and PERK, meaning that cisplatin induced ER stress in NSCLC cells dose-dependently.

Autophagy is a common process in cellular health. Autophagy maintains cell homeostasis by degrading the intracellular aggregation of misfolded proteins and damaged organelles (11). The key event of autophagy is autophagosome formation, and Beclin1 is integral in this process. LC3-II is involved in autophagosomal membrane formation associated with the completion of various cell processes. The ratio of LC3-II to LC3-II I is used to evaluate autophagy levels (27). Abundant research suggests that autophagy plays an important role in regulating chemoresistance in multiple types of cancer cells. A study by Fukuda et al. reported that autophagy was related to endometrial tumor growth and cisplatin resistance, and that the inhibition of autophagy overcame the cisplatin resistance of endometrial cancer cells (28). Furthermore, the inhibition of autophagy was reported to enhance cisplatininduced cell death and apoptosis in human ovarian cancer cells (13). The present study found that cisplatin increased the expression of Beclin 1 and promoted transformation of LC3-I to LC3-II, suggesting that cisplatin advances autophagy in NSCLC cells.

Recently, traditional Chinese medicine has gained significant attention because of its potential antitumor activities. AS-IV is a major active ingredient of Astragalus membranaceus, a medicinal plant commonly used in East Asia (29). Accumulating evidence suggests that AS-IV can exert multiple anti-inflammatory and anti-oxidative functions, and it has been used often for the treatment of cardiovascular diseases (30), exerting its anti-tumor effects to this end. AS-IV was also observed inhibiting colorectal cancer epithelial-mesenchymal transition by promoting miR-134 expression level which dramatically inhibited the recombinant human cAMP responsive element binding protein (CREB1) signaling pathway, and therefore enhanced the sensitivity to chemotherapy (31). Additionally, it was also shown that AS-IV also sensitizes NSCLC cells to gefitinib via the regulation of Sirtuin 6 (SIRT6) (32). In the current study, our results demonstrated that cisplatin treatment combined with AS-IV dramatically enhanced cisplatin sensitivity in NSCLC cells and enhanced the antitumor effect of cisplatin. Moreover, we also found that AS-IV inhibited the expression of GRP78 and Beclin1, indicating that AS-IV suppresses ER stress and autophagy in NSCLC cells dose-dependently. Inhibition of ER stress or autophagy both counteracted the inhibitory effect of ASIV on chemoresistance to cisplatin in NSCLC cells. Our results confirm that AS-IV can sensitize NSCLC cells to cisplatin through suppressing ER stress and autophagy.

In summary, this study found that cisplatin triggers autophagy and ER stress which, in turn, increases chemoresistance in NSCLC cells. However, the combination of AS-IV and cisplatin can sensitize NSCLC cells to cisplatin and enhance the antitumor effect of cisplatin by suppressing ER stress and autophagy. These findings provide support for the potential clinical application of AS-IV on cisplatin-resistant NSCLC patients.

\section{Acknowledgments}

Funding: This work was supported by Shanghai Outstanding Young Medical Talents Training Program (QNYXRC01).

\section{Footnote}

Data Sharing Statement: Available at http://dx.doi. org/10.21037/jtd-20-2098 
Conflicts of Interest: All authors have completed the ICMJE uniform disclosure form (available at http://dx.doi. org/10.21037/jtd-20-2098). The authors have no conflicts of interest to declare.

Ethical Statement: The authors are accountable for all aspects of the work in ensuring that questions related to the accuracy or integrity of any part of the work are appropriately investigated and resolved.

Open Access Statement: This is an Open Access article distributed in accordance with the Creative Commons Attribution-NonCommercial-NoDerivs 4.0 International License (CC BY-NC-ND 4.0), which permits the noncommercial replication and distribution of the article with the strict proviso that no changes or edits are made and the original work is properly cited (including links to both the formal publication through the relevant DOI and the license). See: https://creativecommons.org/licenses/by-nc-nd/4.0/.

\section{References}

1. Jemal A, Bray F, Center MM, et al. Global cancer statistics. CA Cancer J Clin 2011;61:69-90.

2. Lee RC, Thapa B, John T. LACES and bootstraps: the hunt for prognostic and predictive markers for adjuvant therapy in NSCLC. Transl Lung Cancer Res 2018;7:S239-42.

3. Wu DW, Lee MC, Hsu NY, et al. FHIT loss confers cisplatin resistance in lung cancer via the AKT/NFkappaB/Slug-mediated PUMA reduction. Oncogene 2015;34:3882-3.

4. Zhang R, Wang R, Chen Q, et al. Inhibition of autophagy using 3-methyladenine increases cisplatininduced apoptosis by increasing endoplasmic reticulum stress in U251 human glioma cells. Mol Med Rep 2015;12:1727-32.

5. Shi S, Tan P, Yan B, et al. ER stress and autophagy are involved in the apoptosis induced by cisplatin in human lung cancer cells. Oncol Rep 2016;35:2606-14.

6. Lin YD, Chen S, Yue P, et al. CAAT/enhancer binding protein homologous protein-dependent death receptor 5 induction is a major component of SHetA2-induced apoptosis in lung cancer cells. Cancer Res 2008;68:5335-44.

7. Ron D, Hubbard SR. How IRE1 reacts to ER stress. Cell 2008;132:24-6.

8. Dong D, Ni M, Li J, et al. Critical role of the stress chaperone GRP78/BiP in tumor proliferation, survival, and tumor angiogenesis in transgene-induced mammary tumor development. Cancer Res 2008;68:498-505.

9. Bernales S, Papa FR, Walter P. Intracellular signaling by the unfolded protein response. Annu Rev Cell Dev Biol 2006;22:487-508.

10. Lin JH, Walter P, Yen TS. Endoplasmic reticulum stress in disease pathogenesis. Annu Rev Pathol 2008;3:399-425.

11. Jonckheere N, Van Seuningen I. Fine-tuning autophagy in pancreatic adenocarcinoma: full blockage is required. Ann Transl Med 2019;7:S43.

12. Kim MO, Lee HS, Chin YW, et al. Gartanin induces autophagy through JNK activation which extenuates caspase-dependent apoptosis. Oncol Rep 2015;34:139-46.

13. Bao L, Jaramillo MC, Zhang Z, et al. Induction of autophagy contributes to cisplatin resistance in human ovarian cancer cells. Mol Med Rep 2015;11:91-8.

14. Su Z, Li G, Liu C, et al. Autophagy inhibition impairs the epithelial-mesenchymal transition and enhances cisplatin sensitivity in nasopharyngeal carcinoma. Oncol Lett 2017;13:4147-54.

15. Li J, Huang L, Wang S, et al. Astragaloside IV attenuates inflammatory reaction via activating immune function of regulatory T-cells inhibited by HMGB1 in mice. Pharm Biol 2016;54:3217-25.

16. Cai Z, Liu J, Bian H, et al. Astragaloside IV ameliorates necrotizing enterocolitis by attenuating oxidative stress and suppressing inflammation via the vitamin D3-upregulated protein 1/NF-kappaB signaling pathway. Exp Ther Med 2016;12:2702-8.

17. He CS, Liu YC, Xu ZP, et al. Astragaloside IV Enhances Cisplatin Chemosensitivity in Non-Small Cell Lung Cancer Cells Through Inhibition of B7-H3. Cell Physiol Biochem 2016;40:1221-9.

18. Tian L, Zhang J, Ren X, et al. Overexpression of miR-26b decreases the cisplatin-resistance in laryngeal cancer by targeting ATF2. Oncotarget 2017;8:79023-33.

19. Zeng SG, Xie JH, Zeng QY, et al. MicroRNA-4975 p negatively regulates the proliferation and cisplatin resistance of non-small cell lung cancer cells by targeting YAP1 and TEAD1. Transl Cancer Res 2019;8:2470-80.

20. Basu A, Krishnamurthy S. Cellular responses to Cisplatininduced DNA damage. J Nucleic Acids 2010;2010.

21. Moir RD, Gross DA, Silver DL, et al. SCS3 and YFT2 link transcription of phospholipid biosynthetic genes to ER stress and the UPR. PLoS Genet 2012;8:e1002890.

22. Perlmutter DH. Misfolded proteins in the endoplasmic reticulum. Lab Invest 1999;79:623-38.

23. Ruiz A, Matute C, Alberdi E. Intracellular Ca2+ release through ryanodine receptors contributes to AMPA 
receptor-mediated mitochondrial dysfunction and ER stress in oligodendrocytes. Cell Death Dis 2010;1:e54.

24. Hetz C. The UPR as a survival factor of cancer cells: More than folding proteins? Leuk Res 2009;33:880-2.

25. Brewer JW. Regulatory crosstalk within the mammalian unfolded protein response. Cell Mol Life Sci 2014;71:1067-79.

26. Lin Y, Wang Z, Liu L, et al. Akt is the downstream target of GRP78 in mediating cisplatin resistance in ER stress-tolerant human lung cancer cells. Lung Cancer 2011;71:291-7.

27. Klionsky DJ, Cuervo AM, Seglen PO. Methods for monitoring autophagy from yeast to human. Autophagy 2007;3:181-206.

28. Fukuda T, Oda K, Wada-Hiraike O, et al. The antimalarial chloroquine suppresses proliferation and overcomes cisplatin resistance of endometrial cancer cells via autophagy inhibition. Gynecol Oncol 2015;137:538-45.

Cite this article as: Lai ST, Wang Y, Peng F. Astragaloside IV sensitizes non-small cell lung cancer cells to cisplatin by suppressing endoplasmic reticulum stress and autophagy. J Thorac Dis 2020;12(7):3715-3724. doi: 10.21037/jtd-20-2098
29. Zhang A, Zheng Y, Que Z, et al. Astragaloside IV inhibits progression of lung cancer by mediating immune function of Tregs and CTLs by interfering with IDO. J Cancer Res Clin Oncol 2014;140:1883-90.

30. Zhao J, Yang P, Li F, et al. Therapeutic effects of astragaloside IV on myocardial injuries: multitarget identification and network analysis. PLoS One 2012;7:e44938.

31. Ye Q, Su L, Chen D, et al. Astragaloside IV Induced miR-134 Expression Reduces EMT and Increases Chemotherapeutic Sensitivity by Suppressing CREB1 Signaling in Colorectal Cancer Cell Line SW-480. Cell Physiol Biochem 2017;43:1617-26.

32. Dai PC, Liu DL, Zhang L, et al. Astragaloside IV sensitizes non-small cell lung cancer cells to gefitinib potentially via regulation of SIRT6. Tumour Biol 2017;39:1010428317697555.

(English Language Editor: J. Gray) 